\title{
A RENÚNCIA AOS BENS MUNDANOS DE GIOTTO DI BONDONE: REFLEXÕES ACERCA DA INFÂNCIA NA IDADE MÉDIA
}

\author{
The renounce of worldly goods of Giotto Di Bondone: reflections about the \\ childhood in the Middle Age
}

\section{La renuncia a los bienes mundanos de Giotto Di Bondone: reflexiones acerca de la infancia en la Edad Media}

\author{
Meire Aparecida Lóde Nunes* \\ Terezinha Oliveira* \\ Sthefany Matheus da Silva*
}

\begin{abstract}
Resumo
O objetivo do texto é refletir acerca do conceito de infância na Idade Média por meio da análise iconográfica da obra de Giotto Di Bondone, Renuncia aos bens mundanos. A delimitação do período, Idade Média, decorre-se do fato do conceito de infância medieval ser distante do contemporâneo, pois, de acordo com o estudioso Philippe Ariès (1978), as crianças eram adultos em miniaturas. O estudo tem como método reflexivo a História Social, que permite um diálogo entre diferentes áreas do conhecimento, ampliando as possibilidades de pensar o nosso tempo. Pretendemos, neste artigo, indicar uma possibilidade de análise no qual o conceito de infância possa ser pensado sob uma perspectiva histórica em que se privilegia a vinculação entre a formação da criança e, em concomitância o projeto de sociedade adulta a ser constituída. Assim, nosso discurso será desenvolvido no sentido de evidenciar que na concepção de infância que um dado tempo desenha, está também, delineado o seu entendimento de sociedade. Sob este aspecto, pensar a educação da criança é pensar, também, o desenvolvimento e formação do ser humano.
\end{abstract}

PALAVRAS-CHAVE: Infância. Idade Média. Giotto

\begin{abstract}
*Graduação em Educação Física e Doutorado em Educação pela Universidade Estadual de Maringá (UEM). Docente do curso de Educação Física-UNESPAR. Docente no Programa de Pós-graduação em ensino - PPIFOR/UNESPAR. E-mail: meirelode@gmail.com. Orcid: https://orcid.org/0000-0002-05368117

*Graduação em História pela Universidade Estadual Paulista Júlio de Mesquita Filho. Mestrado em Ciências Sociais pela Universidade Federal de São Carlos. Doutorado em História pela Universidade Estadual Paulista Júlio de Mesquita Filho (UNESP). Pós-Doutorado em História e Filosofia da Educação na Faculdade de Educação da Universidade de São Paulo. Professora Titular da Universidade Estadual de Maringá (UEM) no Departamento de Fundamentos da Educação e do Programa de Pós-graduação em Educação.Diretora da Editora da Universidade Estadual de Maringá (EDUEM).Editora Científica da Revista Acta Scientiarum Education e Imagens da Educação. E-mail: teleoliv@gmail.com. Orcid: https://orcid.org/0000-0001-5349-1059

*Graduada em Educação Física pela Universidade Estadual do Paraná - UNESPAR. E-mail: sthsilva@outlook.com. Orcid: https://orcid.org/0000-0002-3608-3018
\end{abstract}


The goal of this text is to reflect about the concept of childhood in the Middle Age through the iconographic analysis over the works of Giotto Di Bondone, Renounce to the worldly goods. The delimitation of the period, Middle Age, takes place of the fact that the concept of medieval childhood is far from the contemporary, because, according to the studious Philippe Ariès (1978), the children were adults in miniature. The study has as reflexive method the Social History, which makes possible a dialogue between different knowledge areas, expanding the possibilities of thinking in our time. We intend, in this article, indicate a possibility of analysis in which the concept of childhood can be linked in a historical perspective which privileges the link between the formation of the child and, in concomitance the project of adult society to be constituted. Like this, our speech will be developed in a way to evidence that the conception of childhood which a determined time draws, is also, outlined their understanding of society. Under this view, thinking the education of a child is to think, too, the development and formation of the human being.

KEYWORDS: Childhood. Middle Age. Giotto

\section{Resumen}

El objetivo del texto es reflexionar acerca del concepto de infancia en la Edad Media por medio del análisis iconográfico de la obra de Giotto Di Bondone, Renuncia a los bienes mundanos. La delimitación del período, Edad Media, se deriva del hecho de que el concepto de infancia medieval es distante del contemporáneo, pues, de acuerdo con el estudioso Philippe Ariès (1978), los niños eran adultos en miniaturas. El estudio tiene como método reflexivo la Historia Social, que permite un diálogo entre diferentes áreas del conocimiento, ampliando las posibilidades de pensar nuestro tiempo. Pretendemos en este artículo indicar una posibilidad de análisis en el cual el concepto de infancia pueda ser pensado bajo una perspectiva histórica en que se privilegia la vinculación entre la formación del niño y, en concomitancia el proyecto de sociedad adulta a ser constituida. Así, nuestro discurso será desarrollado en el sentido de evidenciar que en la concepción de infancia que un dado tiempo dibuja, está también, delineado su entendimiento de sociedad . En este aspecto, pensar la educación del niño es pensar, también, el desarrollo y la formación del ser humano.

PALABRAS CLAVE: Infancia. Edad Media. Giotto

\section{INTRODUÇÃO}

A sociedade contemporânea é decorrente de mudanças estruturais, econômicas e culturais que tem suas origens em momentos anteriores ao vivido. Essas mudanças podem ser constatadas, atualmente, por meio do comportamento dos adultos com relação as crianças que, em certa medida, tornaram-se protagonistas das preocupações sociais em oposição a um passado recente, no qual ocupavam um papel secundário, em todos os segmentos sociais. Essa inversão de posição hierárquica que a infância assumiu, pode ser considerada como um avanço na conscientização da necessidade de preservação dos direitos das crianças e, em última instância, da própria preservação da vida infantil. No entanto, todas as mudanças têm suas consequências e, algumas delas, podem não ser totalmente positivas o que requer reflexões e constantes avaliações para que novos caminhos sejam tomados afim de minimizar os problemas existentes. Ilustramos como consequência desse processo o que Zolet (2017) denomina de 'síndrome do imperador': crianças temperamentais e mandonas com propensão a não 
respeitar as regras sociais. A autora explica que essas crianças não passaram por experiências que as levassem a entender que não é possível ter tudo no tempo e modo que desejam, o que interfere na assimilação das regras sociais. No ambiente escolar, a 'síndrome do imperador' se revela por meio de desacatos ao professor, furtos de objetos dos colegas e constantes mentiras. Abordando a mesma 'síndrome' o psicoterapeuta Leo Fraiman ${ }^{1}$ menciona que as atitudes dos pais influenciam diretamente na formação dos filhos e, atualmente, existe uma necessidade paterna que chega a ser nociva, em fazer os filhos felizes. O cuidado excessivo para evitar frustrações poderia induzir a criança a um estado de incapacidade de autonomia, propiciando um desequilíbrio emocional e em última instância, uma sociedade de adultos que não seriam maduros e responsáveis para assumir os papeis sociais necessários à conservação e desenvolvimento da sociedade. É importante ressaltar que as reflexões sobre situações como essa, acerca da infância na contemporaneidade, não podem ser desenvolvidas desconsiderando as condições históricas, políticas e culturais que interferem diretamente na construção acerca das mentalidades sociais, a própria concepção de infância está atrelada ao contexto social.

Assim, ao pensamos na compreensão contemporânea de infância - entendida como um período da vida que se inicia ao nascer e se estende até o início da adolescência, que de acordo com o estatuto da criança e do adolescente, se estende até os doze anos de idade incompletos, (BRASIL, 1990) - é preciso entender que ela não se aplica a outros momentos históricos, como, por exemplo, a Idade Média, onde a infância poderia ser entendia apenas como os anos iniciais, os de mais fragilidade para a manutenção da vida. Ariès (1978, p.14) menciona que é possível ter existido uma certa "[...] ausência do sentimento de infância [...]" naquele período. O olhar para o período medieval, nos permite perceber que existem diversos modos de viver, de pensar e de interpretar a infância, que seu significado é decorrente "[...] das transformações sociais: toda sociedade tem seus sistemas de classes de idade e a cada uma delas é associado um sistema de status e papel" (KUHLMANN, 2011, p.16). Portanto, o conceito de infância deve ser considerado em seu contexto histórico, suas concepções atuam diretamente na formação dos adultos e na constituição e organização social. Desse modo, ressaltamos a necessidade de entender o conceito de infância por reconhecermos que é uma importante fase da vida e fundamental para os estudos que, de forma geral, se preocupam com a educação institucionalizada ou não, mas tem o homem como um todo no centro de seu interesse.

Para estudarmos essas questões, lançamos nosso olhar para os séculos XII e XIII, os quais representam uma grande mudança na forma de pensar e, principalmente, de perceber e tratar a criança. A história assume uma dimensão significativa nesta pesquisa, pois de acordo com Bloch (2001), os conhecimentos do presente não devem ser desvencilhados dos conhecimentos do passado, já que o próprio presente se remete à um passado recente. Nesse sentido, nos aproximamos dos estudos pertinentes a História Social, a qual entende que, "[...] em história, todos os níveis de abordagem estão inscritos no social e se interligam" (CARDOSO; VAINFAS, 1997, p.78). A história social empenha-se nas experiências das pessoas e no passado, dessa maneira, as representações humanas e ações sociais ganham a possibilidade de serem interpretadas (CARDOSO; VAINFAS, 1997).

${ }^{1}$ Entrevista apresentada no dia 26/02/2018 no programa “Tudo seu”. Disponível em: https://www.youtube.com/watch?v=RXHvwnJW9Fs 
Quando consideramos a história nessa perspectiva, podemos considerar a iconografia como fonte de pesquisa, pois mesmo que ambas sejam diferentes, se aproximam na medida em que são áreas resultantes da produção humana e trazem em seu âmago uma questão em comum, o homem. Como Braudel (1978, p. 264) explica, “[...] não há no mundo dos seres vivos senão uma História, a do homem, é preciso que o homem se compare ao homem, que nossa investigação vá de uma experiência a outra, de uma civilização a outra". Nesse processo de investigação que considera as diferentes experiências, o diálogo entre áreas vizinhas do conhecimento constitui-se como um importante procedimento metodológico, pois, "Todas as ciências do homem, inclusive a história, estão contaminadas umas pelas outras. Falam a mesma linguagem ou podem falá-la (BRAUDEL, 1978, p.54)". A iconografia, como um ramo da própria história pode trazer valiosas contribuições para o conhecimento acerca dos homens e suas civilizações. Assim, adotamos como fonte iconográfica as imagens medievais que, dentre outros aspectos, foram importantes veículos pedagógicos, "[...] o que eles não podiam compreender pela leitura, assimilavam pela imagem" (OLIVEIRA, 2009, p.37). Analisaremos a obra de Giotto (1267-1337) Renúncia aos bem mundanos com o objetivo de refletir sobre o conceito de infância na Idade Média. A opção pela pintura, justifica-se pela cena retratar um momento público em que crianças estão presente, o que nos possibilita verificar as aproximações e distanciamentos entre as crianças e os adultos. Com relação ao artista, Giotto di Bondone marcou o início de um "[...] capítulo inteiramente novo na história da arte" (GOMBRICH, 2008, p.205). As mudanças inseridas por Giotto colocam o homem comum como protagonista dos adventos sociais, o que nos possibilita supor que adultos e crianças são apresentadas pelo artista de forma próxima a realidade daquela sociedade.

O desenvolvimento do estudo ocorrerá em dois momentos: primeiramente buscamos nos aproximar do contexto medieval, especificamente dos séculos XII e XIII, tendo como direcionamento reflexivo o conceito de infância; na sequência, passamos à análise da imagem.

\section{Uma concepção de infância na Idade Média}

Franco Júnior (2001) entende que quando nos referimos a momentos anteriores ao nosso há uma tendência em rotulá-los, assim o conceito de Idade Média foi criado pelos homens do século XVI, considerando-o como uma interrupção no avanço da humanidade, até mesmo, entendido como Idade das Trevas. O autor ressalta que a Idade Média foi um período que durou cerca de um milênio, mesmo que não se tenha claramente seu marco cronológico inicial, tem-se como ponto de partida várias datas marcadas por momentos particulares da história tanto em seu contexto político, religioso e econômico. O mesmo ocorre com seu término. Não há uma unanimidade no que se refere à passagem da Antiguidade para a Idade Média, ou mesmo para a transição da Idade Média para a Moderna.

Umberto Eco ressalta que mesmo com tantos estereótipos "[...] a Idade Média não é o que o leitor comum pensa, o que muitos manuais escolares compostos à pressa fazem crer e que o cinema e a televisão têm apresentado" (ECO, 2010, p.4). Mesmo que nos dias atuais ainda haja resquícios de uma concepção obscura, essa visão pessimista apresentada a nós seria, segundo estes autores, equivocada ou até mesmo forjada. A Idade Média não foi apenas uma fase intermediária entre as civilizações antiga e 
moderna, mas sim, um período de grandes transformações que marcaram o início da modernidade (NUNES, 1979). Como exemplo de desenvolvimento intelectual, destacase o século XII. Sobre esse século Le Goff menciona que foi um momento que ocorreu "[...] um renascimento intelectual, um movimento de renovação social e ideológica nascido de um grande avanço econômico. [...] Esse avanço cultural integrou-se ao desabrochar geral da sociedade" (LE GOFF, 2010, p. 32). Nesse mesmo período (séculos XII e XIII), a sociedade ocidental conheceu um grande avanço populacional e territorial que proporcionou um desenvolvimento nas artes, na literatura, no ensino, na filosofia, entre outros (FRANCO JÚNIOR, 2001, p. 001). Observa-se, desse modo, o desenvolvimento das escolas urbanas e um consequente avanço na alfabetização e educação das crianças, mesmo que não tenha atingido uma parcela significativa da população, esse movimento não pode ser ignorado.

O surgimento das escolas foi, para Philippe Ariès (1978), uma das primeiras formas de diferenciar as crianças dos adultos, pois, a transmissão de valores e conhecimentos até então, ocorria por meio da socialização com os adultos, ou seja, a criança aprendia ajudando a fazer as atividades diárias. $\mathrm{Na}$ escola o aprendizado não aconteceria mais em forma de socialização direta, mas sim, por meio de uma instituição, a criança naquele momento passa a ter uma maior atenção. Subentende-se, dessa forma, que a criança começou a ser diferenciada dos adultos e ter uma valorização por meio da criação das escolas. Em momentos anteriores "A passagem da criança pela família e pela sociedade era muito breve e muito insignificante para que tivesse tempo ou razão de forçar a memória e tocar a sensibilidade [...] a criança não chegava a sair de uma espécie de anonimato" (ARIĖS, 1978, p.10).

Ariès (1978) ressalta que nem mesmo a arte da época procurava representar a criança, supondo assim, um desconhecimento da infância. O autor chama atenção para alguns casos em que crianças eram representadas como adultos em miniatura. Um desses casos é uma miniatura otoniana do século XI (Evangeliário de Oto III, Munique), tendo como tema, uma cena em que Jesus deixa vir até ele às criancinhas, outra é uma miniatura francesa, também do século XI, que representa as três crianças que São Nicolau ressuscita e no evangeliário da Sainte-Chapelle, do século XIII, que representa a multiplicação dos pães. A partir dessas cenas, o autor afirma que as crianças não possuíam características físicas próprias da infância, se diferenciando do adulto apenas por um aspecto: o tamanho. Dessa maneira, Ariès destaca que não era perceptível a passagem da infância para a idade adulta. Entretanto, o historiador também nos coloca que por volta do século XIII, começaram a surgir alguns trabalhos nos quais as crianças começaram a ser representadas de modo mais próximo ao olhar moderno.

No entanto, Le Goff (2006) em Uma História do corpo na Idade Média, nos permite entender a infância diferentemente de Ariès. $\mathrm{O}$ autor apresenta uma perspectiva denominada como 'idades da vida' a qual nos mostra que a Idade Média possuía uma periodização herdada da Antiguidade, como a de Aristóteles que atribuía à vida três fases -crescimento, estabilidade e declínio - e de Pitágoras que a dividia em quatro fases de vinte anos cada uma: criança, jovem, homem adulto e velho.

Essas quatro idades da vida serão encontradas na Idade Média, sobretudo em Alberto, o Grande, porque tinha a vantagem de dar conta das mudanças importantes do corpo humano e de uma visão biológica mais cadenciada (trinta, quarenta e sessenta anos). (LE GOFF, 2006, p. 95). 
Le Goff (2006), também, ressalta o surgimento do algarismo 7 herdado dos gregos, que dividia a vida em sete partes "[...] do nascimento ao sétimo ano (infantia), dos sete aos quatorze anos (pueritia), dos quatorze aos vinte e oito anos (adulescentia), dos vinte e oito aos cinquenta anos (juventus), dos cinquenta aos setenta anos (gravitas)" (LE GOFF, 2006, p.95). Por último, destaca que na 'Idade Média Tardia' surgiram as 12 idades da vida ilustrado em um poema anônimo do século XIV, Lesdouze móis figurez. Dessa forma, podemos entender que havia uma consciência e distinção entre infância e idade adulta, o que dificulta uma generalização acerca da afirmativa de que durante a Idade Média existia uma ausência do conceito de infância. Talvez, poderíamos supor que a infância possuía acepções diferentes com relação aos aspectos culturais e biológicos, os quais interferiam diretamente no trato com a criança medieval.

Contudo, vários autores são partidários do posicionamento de Àries, entre eles Heywood (2004), para o qual as crianças só começaram a ter, pelos adultos, o reconhecimento de suas características por volta dos séculos XV, XVI e XVII "[...] quando então se reconheceria que as crianças precisavam de tratamento especial" (HEYWOOD, 2004, p.23). Para esses autores, foi somente nesse momento que as crianças deixaram de ser tratadas como adultos e passou a se reconhecer que ela precisaria receber cuidados e atenções especiais.

$O$ pensamento de que a infância surge na modernidade, pode ser pensado considerando dois aspectos presentes na Idade Média: a baixa expectativa de vida no período e o grande índice de mortalidade infantil. Com relação a expectativa de vida daquela época percebemos que as pessoas não tinham uma longevidade com a qual nos deparamos atualmente. Le Goff (2006) ressalta que, de acordo com historiadores com formação em demografia, a expectativa de vida variava em uma média de trinta e cinco e quarenta anos de idade. Ariès e Duby (2009) também consideram que a expectativa de vida era baixa, sendo as pessoas com quarenta anos consideradas velhas. Podemos assim entender a Idade Média como uma "[...] sociedade de gente que morria cedo, de guerreiros e camponeses que só tinham valor quando estavam em seu pleno vigor físico" (LE GOFF, 2006, p.311). Se tratando de uma população que sofria com epidemias e doenças que ceifavam a sociedade, tornando-a cada vez menos numerosa (ECO, 2010), ou seja, uma sociedade em que se vivia pouco, era preciso otimizar o tempo de vida das pessoas. Dedicar muitos anos na preparação para a vida adulta, poderia não ter sentido, uma vez que sua permanência nessa fase era curta, ou poderia nem ser alcançada, já que a mortalidade infantil, também, era alta.

Le Goff (2006, p.93) traz a informação de que "[...] As escavações nos cemitérios ainda encontram dificuldades para determinar a expectativa de vida dos homens da Idade Média, mas permitem considerar que a mortalidade infantil era muito importante". Ariès nos chama atenção para essa mortalidade infantil, quando destaca que "[...] Se ela morresse então, como muitas vezes acontecia, alguns podiam ficar desolados, mas a regra geral era não fazer muito caso, pois uma outra criança logo a substituiria" (ARIÈS, 1978, p.10). Esse fato nos leva a inferir que a morte de crianças era um acontecimento banal. Heywood (2004, p.87), reafirma essa suposição quando menciona que as crianças com menos de dois anos sofriam ainda mais com o descaso, pois não era "[...] aconselhável investir muito tempo ou esforço em um 'pobre animal suspirante', que tinha tantas probabilidades de morrer com pouca idade" (HEYWOOD, 
2004, p.87). Sendo assim, em função dessa baixa expectativa de vida e do grande índice de mortalidade infantil não havia uma grande 'preocupação' com a criança. Esses dois fatores poderiam ter influenciado o conceito de infância da época: como as pessoas não viviam muito, possivelmente não se poderia permanecer no período da infância por tempo prolongado.

Desse modo, quando voltamos nosso olhar para esse período histórico, percebemos a existência de um conceito de infância, no entanto, diferente do que temos nos dias atuais devido a vários fatores (sociais, econômicos, geográficos, entre outros). O conceito de infância estava vinculado a uma dependência do adulto, a saída desse período ocorria quando a criança não precisava de seus cuidados básicos, por exemplo, para se alimentar e locomover. Nesse momento, quando possuía autonomia física, ela estava preparada para ser instruída e inserida na sociedade contribuindo para sua manutenção e desenvolvimento. Mesmo considerando que as condições de inserção social podem ser as mesmas para os dois períodos, atualmente, parece-nos, que o conceito de infância não está vinculado a autonomia física da criança.

Ao pensarmos sobre o conceito de infância medieval atrelado a autonomia física dos homens, nos aproximamos dos pensamentos do filósofo moderno Kant quando aborda questões acerca da educação. Para esse filósofo "O Homem é a única criatura que precisa ser educada. Por educação entende-se o cuidado de sua infância (a conservação, o trato), a disciplina e a instrução com a formação" (KANT, 1999, p. 11). $\mathrm{O}$ cuidado refere-se ao período em que a criança depende dos pais para manterem-se vivas, após essa fase é preciso que a educação exerça outras funções as quais propiciem a autonomia, para além da física, pois essa ele já alcançou. A autonomia, na perspectiva kantiana, pode ser entendida por meio de suas explicações sobre 'esclarecimento', que para ele é 'saída da menoridade', entendida como "[...] a incapacidade de servir-se do próprio entendimento sem direção alheia." (KANT, 2009, p. 407). Para Kant, a culpa do homem permanecer nesse estado é dele próprio por não se desvencilhar do direcionamento de seus tutores, "A inercia e a covardia são as causas de uma tão grande maioria de os homens, mesmo depois de a natureza de há muito tê-los libertado de uma direção alheia (naturalitermaiorennes), de bom grado permaneça toda vida na menoridade" (KANT, 2009, p. 407). Essas questões apresentadas por Kant nos possibilitam pensar sobre a contradição presente no conceito de infância na Idade Média e na contemporaneidade. Parece-nos que no medievo a infância era compreendida como o período dos cuidados, quando capaz de sobreviver sem a dependência dos pais, seria atribuída às crianças, certa, autonomia. Essa realidade parece muito distante da perspectiva contemporânea de infância, a qual vem sendo prolonga cada vez mais. Kant nos apresenta a possibilidade de pensar essa situação quando menciona que:

É tão cômodo ser menor. Possuo um livro que faz as vezes de meu entendimento, um guru espiritual que faz as vezes de minha consciência, um médico, que decide por mim decide a dieta, etc., assim, não preciso eu mesmo dispender nenhum esforço. Não preciso necessariamente pensar, se posso apenas pagar; outros se incumbirão por mim dessa aborrecida ocupação (KANT, 2009, p. 407).

Nesse sentido, pensamos a responsabilidade dos adultos na formação das novas gerações. Pais e professores, por exemplo, podem ser considerados os tutores 
mencionados por Kant, que contribuem de 'bom grado' para a formação de uma sociedade de pessoas que permanecem eternamente na menoridade. Os tutores,

\begin{abstract}
Após terem emburrecido seu gado doméstico e cuidadosamente impedido que essas dóceis criaturas pudessem dar um passo fora do andador, mostramlhes em seguida o perigo que paira sobre elas, caso procurem andar por própria conta e risco. Ora, este perigo nem é tão grande, de algumas quedas finalmente aprenderiam a andar; mas um exemplo assim dá medo e geralmente intimida contra toda nova tentativa. (KANT, 2009, p. 407-408).
\end{abstract}

Face ao exposto, podemos pensar que a mentalidade social sobre a infância é decisiva para a formação dos adultos, os quais por sua vez serão responsáveis pela manutenção social, por meio de suas próprias ações e pela formação de outros homens. É nessa perspectiva que passamos, na sequência, a analisar a pintura de Giotto para verificar como a mentalidade social acerca da infância foi registrada na arte do século XIII.

\title{
A infância em "Renúncia aos bens mundanos" de Giotto di Bondone
}

Giotto (Ambrogiotto) di Bondone (1267-1337) pintor italiano, do século XIII, era considerado como o "[...] último dos grandes artistas da Idade Média. Outros preferem considerá-lo o primeiro artista moderno [...]" (TREVISAN, 2003, p. 185). Tendo ele nascido por volta do ano de 1267 em Colle di Vespignano, em Mugello, próximo de Florença, várias são as histórias de como se tornou um grande pintor, o que torna sua biografia um tanto quanto incerta. De origem humilde, alguns autores consideram que, em sua infância, Giotto era pastor de ovelhas e teria sido descoberto pelo respeitado pintor Cimabue, aos dez anos de idade, enquanto pastorava e pintava ovelhas, outros consideram que isso é apenas um mito. Entretanto, Giotto tornou-se discípulo de Cimabue, acompanhando o mestre em seus trabalhos em Roma e em Assis.

De acordo com Cecchi (2011), Giotto foi quem iniciou uma grande revolução na forma de representar o mundo, marcando um novo capítulo na história das artes, inovando a linguagem figurativa italiana. Gombrich (2007, p.201) ressalta que o artista foi considerado como "[...] um gênio que quebrou o sortilégio do conservadorismo bizantino". Isso porque, foi ele quem redescobriu a arte de criar a ilusão de profundidade em superfícies planas, o que possibilitou a mudança de concepção de pintura da época.

Desse modo, entre tantas obras de Giotto, a imagem escolhida para orientar as reflexões acerca da infância é a Renúncia aos bens mundanos, a qual faz parte dos afrescos do ciclo da vida de São Francisco e está na parte superior da basílica de Assis (Assis-Itália). A cena pintada por Giotto foi descrita no capítulo II, § 4 da Legenda Maior, escrita em 1260 por Boaventura, a qual o artista manteve-se fiel.

O texto de Boaventura menciona que Francisco foi levado frente ao bispo da cidade para que renunciasse os direitos que tinha dos bens paternos, o que fez sem hesitar ao tirar todas as roupas e devolve-las ao seu pai terreno. Giotto registrou o momento em que Francisco já estava nu e o pai restituído de seus bens, simbolizado pelas roupas do filho, inclusive as intimas, que segura firmemente. 


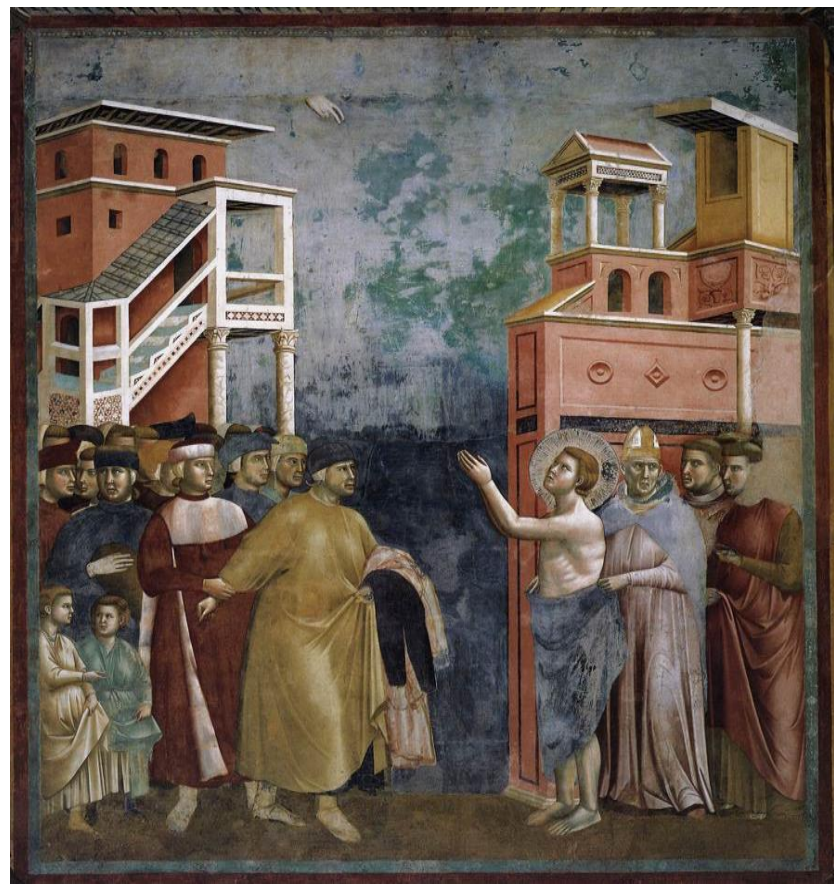

Figura 1. Giotto Di Bondone. Renúncia aos bens mundanos. (170x230). Assis- Itália, Igreja de São Francisco, Igreja de cima ( $3^{\text {a }}$ seção, parede norte)

Fonte: https://www.wga.hu/index1.html

A cena é construída em um ambiente público, como Boaventura informa, na praça do bispo. Há dois grupos bem distintos, um em oposição ao outro, que representam o embate entre a igreja e a comunidade burguesa em ascensão, a qual pertencia a família de Francisco. De acordo com Wolf (2007), a distância entre os grupos expressa um certo repudio do grupo dos comerciantes de Assis diante da ação protagonizada por Francisco e acolhida pelos membros da igreja que estão logo atrás do jovem despido. Boaventura narra a ação do bispo mencionando que:

Vendo isso, e admirado de um fervor tão transbordante no homem de Deus, o bispo logo se levantou recolhendo-o entre seus braços com lágrimas, e, como era um homem piedoso e bom, cobriu-o com o manto que vestia, mandando aos seus que lhe dessem alguma coisa para cobrir os membros do corpo (L/M, 2, 4).

O ápice da revolta contra a cena que acontece em praça pública é expressa com o gesto do próspero comerciante italiano e pai de Francisco, Pietro di Bernadone, que com a mão esquerda segura as vestes do filho e com a direta tenta ataca-lo, mas é contido por um homem que segura sua mão. Wolf atenta para o fato da participação da população na cena, o que não acontecia nas pinturas anteriores. Giotto insere pessoas comuns na narrativa, principalmente por meio dos olhares direcionados, ou não, a Francisco, os quais condenam, aprovam e comentam a nudez do jovem de Assis. Os olhares acompanhados, das fisionomias confusas, expressam a surpresa da qual foram acometidas pela atitude inesperada de um filho de burguês que opta pela pobreza ao invés da vida luxuosa que a condição familiar lhe propiciaria. No entanto, Francisco ignora todos aqueles olhares, e lança o seu em direção ao céu e, de braços estendidos em 
posição de oração, espera a aprovação divina de sua escolha. Por entre as nuvens, a mão de Deus surge abençoando o jovem, a qual parece ser vista apenas por Francisco, pois nem mesmo o bispo que cobre sua nudez com o manto que vestia, tem o olhar em direção do céu, ao contrário, inclina a cabeça na direção oposta a de Deus.

Assim como as demais pessoas que compõem a cena, participando efetivamente do acontecimento público, Giotto pinta duas crianças no canto inferior e esquerdo do afresco. A localização que o pintor atribui as crianças, na frente das demais pessoas, demonstra a sua preocupação em pô-las em evidência. Giotto parece estabelecer uma sequência ordenada para o olhar do observador, nessa ordenação, o olhar para as crianças não está distante do de Francisco, que ocupa a primeira posição. $\mathrm{O}$ uso das cores, pode contribuir para a ideia de aproximação entre o tema central e a representação das duas crianças. As cores claras usadas para iluminar a pintura e realçar detalhes importantes, são as mesmas usadas para colorir as vestes das crianças. Nesse mesmo sentido, podemos destacara aproximação da tonalidade da pele das crianças e a de Francisco, a qual é distante da tonalidade mais escura da pele das demais pessoas que compõem a cena. No entanto, as crianças fazem parte do grupo daqueles que desaprovam a ação de Francisco e, consequentemente, que defendem os bens materiais, opondo-se ao grupo que defende a pobreza material e prol da riqueza espiritual. Assim, as crianças identificam-se com a sociedade da qual fazem parte se distanciando da imagem angelical que lhes são atribuídas frequentemente na arte.

É possível supor que as crianças sejam meninas, as dissemelhanças com os traços dos rostos dos demais personagens masculinos que compõem a pintura e suas vestes, fundamentam essa suposição. As vestes que acentuam os 'seios' podem justificar a tese de Ariès $(1978$, p.69) ao afirmar que até o século XIII nem mesmo as vestes diferenciavam a criança de um adulto "[...] assim que a criança deixava os cueiros, ou seja, a faixa de tecido que era enrolada em torna de seu corpo, ela era vestida como os outros homens e mulheres de sua condição". Entretanto, as roupas das crianças se diferenciam das demais pelo decote em ' $\mathrm{V}$ ', as demais têm as golas arredondadas, e pela suave demarcação na altura da cintura. Essas diferenças podem ser decorrentes dos modelos de roupas de homens e de mulheres e, nesse sentido, as crianças seriam as únicas personagens femininas a compor a cena. Nessa perspectiva, a diferenciação das vestes seria com relação ao gênero e não com a faixa etária. A fisionomia das crianças não é um ponto que permite, de imediato, a diferenciação dos adultos, mas um olhar mais atento pode inferir que seus rostos iluminados apresentam um formato mais arredondado característico da infância que se opõe aos alongados rostos dos adultos. Essa observação pode ser associada a de que as crianças são as únicas, na imagem, que não usam nenhum adereço sobre a cabeça que eram muito comum na indumentária tanto masculina como feminina do período.

Aparentemente, as crianças estão desacompanhas, não há nenhuma aproximação de adultos que nos possibilita supor a presença de um responsável. De forma independente, mas inseridas no mundo dos adultos, elas interagem entre si, acompanham e participam da cena com os olhares. Uma delas, a de vestes claras, reforça a participação infantil com a posição da mão direita que, estendia em direção a Francisco, expressa o seu envolvimento com a narrativa. No entanto, o envolvimento pode ser ampliado quando observamos que guardam alguma coisa em seus vestidos. Entre os interpretes da cena, é aceita a ideia de que os personagens infantis carregam com sigo pedras que aludem a um apedrejamento, o qual é previsto de Deuteronômio: 
Quando alguém tiver um filho contumaz e rebelde, que não obedecer à voz de seu pai e à voz de sua mãe, e, castigando-o eles, lhes não der ouvidos; Então seu pai e sua mãe pegarão nele, e o levarão aos anciãos da sua cidade, e à porta do seu lugar; E dirão aos anciãos da cidade: Este nosso filho é rebelde e contumaz, não dá ouvidos à nossa voz; é um comilão e um beberrão. Então todos os homens da sua cidade o apedrejarão, até que morra; e tirarás o mal do meio de ti, e todo o Israel ouvirá e temerá. (DT, 21:18-21)

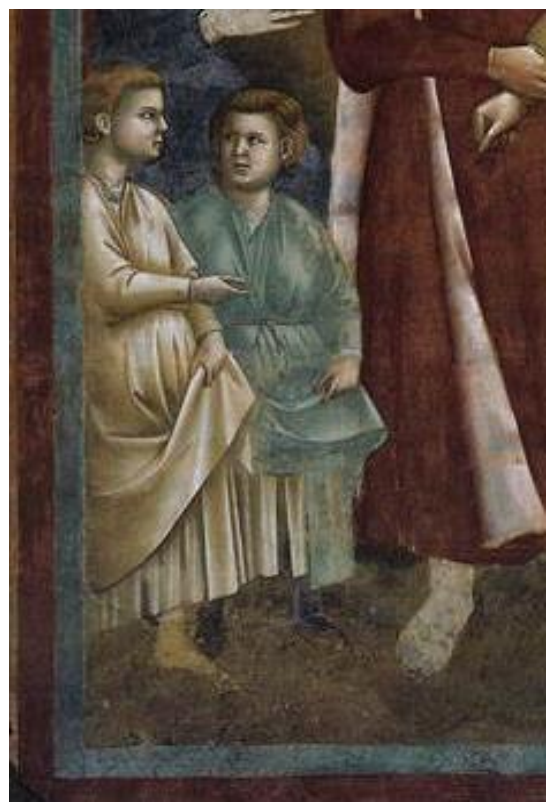

Figura 2. Giotto Di Bondone. Renúncia aos bens mundanos (Detalhe). Assis- Itália, Igreja de São Francisco, Igreja de cima ( $3^{\mathrm{a}}$ secção, parede norte)

Fonte: https://www.wga.hu/index 1.html

Podemos inferir, pela narrativa pintada por Giotto, que as crianças participam dos acontecimentos da sociedade de forma semelhante aos adultos. Elas estavam inseridas, aparentemente, de forma independente na vida pública. No entanto, o pintor nos possibilita pensar sobre uma diferenciação na representação infantil e adulta, inclusive, atribuindo uma posição privilegiada as crianças. As observações não são suficientes para afirmações, mas nos possibilita entender que a pintura de Giotto pode expressar um conceito intermediário no que se refere as afirmações acerca da inexistência de infância medieval. Ainda nos possibilita entender que a infância na Idade Média existia e sua valorização era condizente com o próprio contexto, que evidencia a necessidade de pensarmos os conceitos de acordo com a temporalidade e aludindo para os riscos de seu uso em períodos históricos distintos.

\section{CONSIDERAÇÕES FINAIS}

Por meio desse estudo, ficou-nos evidente a impossibilidade de afirmarmos que na Idade Média não se tinha uma delimitação com relação as fases da vida, como mostrou Le Goff ao tratar da herança da Antiguidade com relação a essa questão. Assim, quando nos deparamos com o posicionamento de que na Idade Média a infância era desconhecida, parece-nos que esse pensamento não pode ser generalista. Há a 
necessidade de entendê-lo considerando as especificidades do período como, os fatores sociais, econômicos, religiosos, familiares, políticos e principalmente a expectativa de vida do homem medieval. No entanto, é inegável que naquela época a preocupação, o trato e a inserção social das crianças se distanciam muito do contexto contemporâneo.

A análise da pintura de Giotto nos mostra que, no século XIII, as crianças desde cedo eram inseridas no mundo adulto. Ao participarem ativamente de uma das cenas mais marcante na história da vida de Francisco de Assis expressam o papel social que desempenham na sociedade daquele momento. Inferência que se torna significativa ao considerarmos que o artista pré-renascentista representava pessoas comuns em ações corriqueiras o que confere uma possível aproximação da infância na sociedade medieval. Entendemos que a obra analisada foi pintada no período que os autores entendem como início da concepção de infância medieval, nesse sentido, as observações da obra reafirmariam a tese da inexistência da diferenciação da criança na Idade Média. Todavia, relembramos a concepção de que as mudanças são lentas e decorrentes de processos iniciados anteriormente, nesse sentido, podemos admitir que a consciência de uma certa diferenciação entre as crianças e os adultos já estava presente na sociedade medieval anteriormente ao período em questão.

Dessa forma, as reflexões desenvolvidas nesse texto não nos permitem, nesse momento, contestar e nem reafirmar a perspectiva de infância que a tradição acadêmica atribuiu à Idade Média, mas nos instiga a ampliar nossas investigações sobre essa questão. Assim, entendemos a importância desse trabalho por possibilitar aos profissionais da Educação um aprofundamento referente aos conhecimentos sobre a infância, fase de grande importância na formação do homem adulto. Os conhecimentos sobre esse período da vida possibilitam entender que as crianças apresentam características próprias de sua idade e entender que o conceito que temos atualmente nem sempre foi dessa maneira, em cada época a infância pode ser entendida de diferentes formas. Além da possibilidade de entender que, por meio do ponto de vista histórico, podemos compreender muito sobre os conceitos contemporâneos e, à volta ao passado, nos permite perceber que a criança é um sujeito histórico.

\section{REFERÊNCIAS}

ARIÈS, Philippe. História social da criança e da família, Rio de Janeiro: Zahar, 1978.

BLOCH, Marc. Apologia da história: ou o ofício de historiador, Rio de Janeiro: Zahar, 2001.

BOAVENTURA. "Legenda Maior”. In: SILVEIRA, Ildefonso (Org.); REIS, Orlando dos (Org.). São Francisco de Assis: escritos, biografias, crônicas e outros testemunhos do primeiro século franciscano. 9. ed. Petrópolis: Vozes, 2000, p. 461-610.

BRASIL. Estatuto da Criança e do Adolescente. Câmera dos Deputados, Lei no 8.069, de 13 de julho de 1990. DOU de 16/07/1990 - ECA. Brasília, DF, 1990.

BRAUDEL, Fernand. Escritos sobre a história. São Paulo: Perspectiva, 1978.

CARDOSO, Ciro Flamarion; VAINFAS, Ronaldo. Domínios da história: ensaios de teoria e metodologia, 5 ed. Rio de Janeiro: Campus, 1997. 
CECCHI, MATEO. Giotto. Roma: ATS ItaliaEditrice, 2011. digital source, 2002.

DUBY, G.; ARIÉS, P. H. História da vida privada: da Europa feudal à renascença. São Paulo: Companhia das. Letras, 2009.

ECO, Humberto. Idade Média: Bárbaros, cristãos e muçulmanos. Córdoba: Dom Quixote, 2010.

FRANCO JÚNIOR, Hilário. A Idade Média: nascimento do ocidente. São Paulo: Brasiliense, 2001.

GROMBRICH, E.H. A história da Arte. Rio de Janeiro: LTC, 2007.

HEYWOOD, Colin. Uma história da infância: Da Idade Média à Época Contemporânea no Ocidente, Porto Alegre: Artmed, 2004.

KANT, Immanuel. Sobre a Pedagogia. Piracicaba: Unimep, 1999.

KANT. Resposta à pergunta: "Que é o Esclarecimento. In: Antologia de textos filosóficos. Curitiba: SEED, 2009.

KUHLMANN JUNIOR, Moysés. Infância e Educação Infantil: uma abordagem histórica, Porto Alegre: Mediação, 2011.

LE GOFF, Jacques; TRUONG, Nicolas. Uma história do corpo na Idade Média. Rio de Janeiro: Civilização Brasileira, 2006.

LE GOFF, Jaques. Uma longa Idade Média. 2 ed. Rio de Janeiro: Civilização Brasileira, 2010.

NUNES, Ruy Afonso da Costa. História da Educação na Idade Média. São Paulo: Editora Pedagógica e Universitária Ltda., 1979.

OLIVEIRA, Terezinha. Um olhar da História da Educação no Educar Medievo: um Diálogo, um Manual e uma imagem (1516-5485). Revista Internacional d'Humanitats, v. XII, p. 27-38, 2009.

TREVISAN, A. O rosto de Cristo. Porto Alegre: AGE, 2003.

WOLF, Norbert. Giotto. Lisboa: Taschen, 2007.

ZOLET, Lilian. Síndrome do imperador: entendendo a mente das crianças mandonas e autoritárias. Foz do Iguaçu: Epígrafe, 2017.

Recebido em: 11/10/2019 
Aprovado em: 14/12/2019 